\title{
ORIGEM E IMPLICAÇÕES DOS ÁCIDOS CARBOXÍLICOS NA ATMOSFERA
}

\author{
Silvia Ribeiro de Souza e Lilian R. Franco de Carvalho
}

Instituto de Química, Universidade de São Paulo, CP 26077, 05513-970 São Paulo - SP

Recebido em 30/8/99; aceito em 17/7/00

\begin{abstract}
ORIGIN AND IMPLICATION OF CARBOXYLIC ACIDS IN THE ATMOSPHERE. A general overview about the ambient levels of low molecular weight carboxylic acids and their possible emission sources, as well as the implication of them in the atmosphere is presented. Carboxylic acids are considered to be one of the dominant classes of organic compounds found in the atmosphere in a variety of phases, such as in rainwater, snow and ice, on aerosol particles and gas phase. They may be originated from biogenic and anthropogenic direct emissions and by photochemical reaction in situ. Emission sources and formation mechanisms of organic acids in the atmosphere are discussed.
\end{abstract}

Keywords: atmospheric carboxylic acids; biogenic and anthropogenic emissions; photochemical reactions products.

\section{INTRODUÇÃ̃O}

Os ácidos carboxílicos são considerados uma classe dominante de compostos orgânicos encontrados na atmosfera por se apresentarem em diversos ambientes. Esta classe de compostos orgânicos tem sido detectada em áreas remotas, marinhas, florestais e urbanas, e os compostos estão distribuídos na atmosfera nas fases gasosa, aquosa e particulada.

$\mathrm{Na}$ fase gasosa, predominam os ácidos carboxílicos voláteis de baixo peso molecular, tais como os ácidos acético e fórmico, os quais por serem solúveis em água são encontrados também na fase aquosa ${ }^{1}$. Por outro lado, os ácidos com volatilidade baixa e peso molecular elevado são encontrados normalmente na fas e particulada, como os ácidos dicarboxílicos (oxálico, succínico, etc.) e os ácidos graxos (palmítico, esteárico)².

Os ácidos carboxílicos podem ser emitidos diretamente da fonte, os poluentes primários, ou podem ser formados na atmosfera através de reações químicas, os poluentes secundári$\mathrm{os}^{3}$.

Apesar dos ácidos inorgânicos terem um papel importante na acidez atmosférica, os ácidos carboxílicos representam de 16 a $35 \%$ da acidez livre nas águas de chuva em ambientes urbanos $^{4}$ e aproximadamente $65 \%$ em áreas remotas ${ }^{5}$. A fração ácida da atmosfera pode ser responsável pela destruição de metais e ligas metálicas expostas ao $\operatorname{ar}^{6}$ e estudos recentes têm mostrado o efeito dos ácidos acético e fórmico na corrosão atmosférica de metais ${ }^{7}$.

Sabe-se que os ácidos carboxílicos em concentrações elevadas são prejudiciais à saúde humana podendo provocar desde irritações nos olhos até problemas respiratórios ${ }^{8}$.

Nos últimos anos, os ácidos orgânicos tem despertado um grande interesse dos pesquisadores devido à diversidade desses compostos na atmosfera. As possíveis fontes de emissão, a formação in situ dos ácidos carboxílicos, bem como a influência das variações climáticas na origem destas espécies têm sido alvo de investigação em vários locais do mundo ${ }^{3}$.

\section{OCORRÊNCIA NA ATMOSFERA}

A poluição atmosférica causada pelo smog fotoquímico envolve a participação de inúmeras reações químicas com diferentes compostos orgânicos voláteis presentes na atmosfera. O conhecimento da composição química do aerossol atmosférico responsável pela formação do smog fotoquímico é fundamental para elucidar as causas que conduzem a formação deste tipo de poluição atmosférica.
A partir de 1970, iniciaram os estudos de caracterização química dos compostos oxigenados envolvidos no processo de smog fotoquímico ${ }^{9,10}$. Desde então, os ácidos orgânicos têm sido detectados em amostras de ar atmosférico nas fases gasosa, aquosa e particulada em diferentes ambientes.

\section{Fase Gasosa}

Os ácidos acético e fórmico presentes na fase gasosa, os ácidos carboxílicos mais abundantes, são considerados constituintes onipresentes da troposfera global ${ }^{11-14}$. Em diferentes partes do mundo têm sido medidos os ácidos acético e fórmico e os níveis ambientais dos mesmos em diferentes ambientes estão apresentados na Tabela 1.

Em concentrações menores, os ácidos de peso molecular mais alto também são encontrados na atmosfera, como os ácidos monocarboxílicos alifáticos de $\mathrm{C}_{3} \quad \mathrm{C}_{10}$. Particularmente, $\mathrm{o}$ ácido propiônico tem sido freqüentemente encontrado em atmosfera de regiões urbanas ${ }^{15,16}$.

Os ácidos dicarboxílicos, espécies menos voláteis, são encontrados predominantemente na fase particulada. Entretanto, estudos demonstram que uma fração pequena dos ácidos oxálico, succínico, malônico e maleico pode estar presente no vapor atmosférico ${ }^{15}$.

Dentre os ceto-ácidos, o ácido pirúvico é a espécie freqüentemente encontrada na fase gasosa. Este ácido tem sido detectado em diferentes ambientes, tais como a floresta Amazônica $^{17,18}$, áreas temperadas, ambiente marinho ${ }^{17}$ e regiões urbanas e rurais ${ }^{19}$.

A influência sazonal no nível ambiental dos ácidos carboxílicos gasosos tem sido observada e, em geral, concentrações mais altas são encontradas no verão. Estudos têm mostrado também que as concentrações diurnas são geralmente superiores às concentrações noturnas ${ }^{11,14,20-22}$.

\section{Fase Aquosa}

Os ácidos acético e fórmico por apresentarem baixo peso molecular e polaridade relativamente alta são solúveis na fase aquosa $^{23}$ e consequentemente estão presentes em quantidades significativas nas amostras de água de chuva, gelo, neve e névoa. Dentre os diversos ácidos orgânicos, os mono e dicarboxílicos, como por exemplo propiônico, maleico, oxálico, pirúvico, láctico e glicólico ${ }^{24,29,30}$ também são encontrados na atmosfera, porém representando uma fração bem menor ${ }^{24-28}$. As concentrações dos diversos ácidos orgânicos em diferentes 
amostras líquidas da atmosfera estão apresentadas na Tabela 2. A quantidade do ácido na fase aquosa é função do coeficiente de partição gás/líquido e da taxa de precipitação da região. Em geral, os níveis destas espécies variam com a estação do ano apresentando um aumento substancial no período que precede o verão ${ }^{11,27,31}$.

\section{Fase Particulada}

Os ácidos dicarboxílicos representam a maior fração dos ácidos orgânicos presentes no material particulado atmosférico. Dentre eles, o ácido oxálico tem sido a espécie majoritária e, em seguida, os ácidos succínico, malônico, maleico, adípico e ftálico ${ }^{10,32,33}$. No aerossol urbano, os ácidos oxálico, malônico e succínico contribuem com aproximadamente $70 \%$ dos diácidos totais ${ }^{34}$. Também, os ácidos oxo-carboxílicos, por exemplo o 8-oxo-octanóico ${ }^{35}$, os ceto-ácidos, como pirúvico e ceto-malônico ${ }^{36}$ e os ácidos graxos, como butírico, valérico e capróico são encontrados no aerossol urbano ${ }^{37}$.
Os ácidos acético e fórmico têm sido detectados no material particulado atmosférico em concentrações baixas, geralmente duas vezes menores do que as concentrações dos ácidos na fase gasosa $^{38}$. Vale ressaltar quando se mede os ácidos orgânicos no material particulado atmosférico, que as espécies formiato e acetato podem estar associadas às partículas na forma de sais.

A ocorrência e a abundância dos ácidos orgânicos no material particulado atmosférico depende das condições meteorológicas e características do ambiente. Em regiões tipicamente urbanas foram detectados concentrações elevadas dos dicarboxílicos, oxo-carboxílicos e ceto-ácidos ${ }^{33,34}$. Por outro lado, no aerossol de áreas florestais e marinhas os ácidos monocarboxílicos são os ácidos majoritários ${ }^{39}$ (Tabela 3).

\section{FONTES E PROCESSOS DE FORMAÇÃO DE ÁCIDOS CARBOXÍLICOS ATMOSFÉRICOS}

Os ácidos carboxílicos são emitidos na atmosfera por fontes antropogênicas e naturais e podem ser formados in situ através

Tabela 1. Níveis ambientais (ppbv) encontrados para os ácidos fórmico e acético na fase gasosa.

\begin{tabular}{lccc}
\hline Região (ambiente) & {$[\mathrm{CHOOH}]$} & {$\left[\mathrm{CH}_{3} \mathrm{COOH}\right]$} & Referência \\
\hline Havaí, EUA(marinha) & $0,2-0,9$ & $0,4-1,2$ & 67 \\
Long Beach, EUA (marinha) & $0,4-12,0$ & $0,1-17,8$ & 68 \\
Baviera, Alemanha (rural) & $0,6-7,0$ & $1,2-7,5$ & 46 \\
Angra, Îndia (rural) & $0,4-4,2$ & $0,2-4,0$ & 69 \\
Exelberg, Áustria (semi-rural) & $0,5-3,8$ & $0,4-0,8$ & 20 \\
Copenhague, Dinamarca (semi-rural) & $0,3-1,5$ & $0,4-2,8$ & 70 \\
Congo, Africa (florestal) & $0,01-5,7$ & $0,01-4,3$ & 14 \\
Altos de Pipe, Venezuela (florestal) & $0,6-1,7$ & $0,4-1,4$ & 71 \\
Amazônia, Brasil (florestal) & $0,4-1,4$ & $0,7-1,8$ & 39 \\
Lille Valby, Dinamarca (suburbano) & $0,1-2,3$ & 70 \\
Frankfurt, Alemanha (suburbano) & $0,2-1,0$ & $0,2-2,1$ & 12 \\
Dayalbagh, Índia (suburbano) & $0,3-3,9$ & $0,7-1,2$ & 72 \\
Califórnia, EUA (urbano) & $1,3-13$ & $0,3-1,7$ & 7,73 \\
Bruxelas, Bélgica (urbano) & $0,9-8,5$ & $1,9-16$ & 70 \\
São Paulo, Brasil (urbano) & $2,5-6,1$ & $1,3-8,1$ & 74,75 \\
Boston, EUA (urbano) & $1,8-15,0$ & $1,5-6,3$ & 76 \\
Boston, EUA (ambiente interno) & $5,6-14,4$ & $0,8-5,4$ & 77 \\
\hline
\end{tabular}

Tabela 2. Ácidos orgânicos encontrados na fase líquida.

\begin{tabular}{|c|c|c|c|c|}
\hline $\begin{array}{l}\text { Natureza } \\
\text { da amostra }\end{array}$ & Região (ambiente) & Ácido orgânico & Concentração ${ }^{a}$ & $\begin{array}{c}\text { Referência } \\
(\mu \mathrm{mol} / \mathrm{L})\end{array}$ \\
\hline \multirow{3}{*}{$\begin{array}{l}\text { Chuva } \\
\text { Chuva }\end{array}$} & Amazônia, Brasil (florestal) & fórmico, acético & 5,$1 ; 3,0$ & 17 \\
\hline & Washington, EUA & & & \\
\hline & (urbano) & fórmico, acético & 6,$2 ; 3,0$ & 26 \\
\hline Chuva & Dayalbagh, Índia (suburbano) & fórmico, acético & 4,$6 ; 4,2$ & 82 \\
\hline Chuva & $\begin{array}{c}\text { Califórnia, EUA } \\
\text { (urbano e suburbano) }\end{array}$ & $\begin{array}{l}\text { fórmico, acético, propiônico, } \\
\text { butírico, monocarboxílicos } \\
\qquad\left(\mathrm{C}_{4}-\mathrm{C}_{9}\right)\end{array}$ & $\begin{array}{l}5,5 ; 5,4 ; 0,48 \\
0,11 ; 11,8\end{array}$ & 36 \\
\hline Chuva & $\begin{array}{l}\text { Tóquio, Japão } \\
\text { (marinha) }\end{array}$ & $\begin{array}{l}\text { glioxílico, pirúvico, benzóico, } \\
\text { dicarboxílicos }\left(\mathrm{C}_{2}-\mathrm{C}_{10}\right)\end{array}$ & $\begin{array}{l}12,9 ; 11,9 ; 3,0 ; \\
83,8^{*}\end{array}$ & 29 \\
\hline Chuva & Los Angeles, EUA (urbano) & ácidos graxos & $15,0 *$ & 24 \\
\hline Nuvem & $\begin{array}{c}\text { Virgínia, EUA } \\
\text { (rural) }\end{array}$ & fórmico, acético & 5,$6 ; 4,1$ & 78 \\
\hline Nuvem & $\begin{array}{l}\text { Califórnia, EUA } \\
\quad \text { (urbano) }\end{array}$ & fórmico, acético & 112,$9 ; 56,2$ & 79 \\
\hline Neblina & $\begin{array}{l}\text { Po Vally, Itália } \\
\text { (rural) }\end{array}$ & fórmico, acético, pirúvico & 39,$2 ; 43,0 ; 4,1$ & 23 \\
\hline Neve & Glacier de la Girose, França & fórmico, acético & 1,$05 ; 0,77$ & 80 \\
\hline Gelo & Antártica & fórmico, acético & 1,$0 ; 0,15$ & 81 \\
\hline
\end{tabular}

a - média das concentrações; * $\mu \mathrm{g} / \mathrm{L}$ 
Tabela 3. Ácidos orgânicos encontrados no aerossol atmosférico em diferentes regiões.

\begin{tabular}{|c|c|c|c|}
\hline Região (ambiente) & Ácido orgânico & Concentraçãao ${ }^{\mathrm{a}}\left(\mathrm{ng} / \mathrm{m}^{3}\right)$ & Referência \\
\hline Amazônia, Brasil (florestal) & fórmico, acético & 24,$5 ; 29,6$ & 39 \\
\hline $\begin{array}{l}\text { Alert, Canadá } \\
\text { (polar) }\end{array}$ & $\begin{array}{l}\text { oxálico, malônico, succínico, glutárico, } \\
\text { adípico, subárico, azeláico, maleico, } \\
\text { fumárico, ceto-malônico, } \\
\text { glioxílico, pirúvico }\end{array}$ & $\begin{array}{c}13,6 ; 2,46 ; 3,73 ; 0,90 ; 0,82 \\
0,15 ; 0,26 ; 0,19 ; 0,14 ; 0,31 \\
1,70 ; 0,13\end{array}$ & 36 \\
\hline $\begin{array}{l}\text { Norte do oceano } \\
\text { Atlântico (marinho) }\end{array}$ & fórmico, acético, oxálico & 1,$8 ; 3,8 ; 4,6$ & 83 \\
\hline $\begin{array}{l}\text { Nova York, EUA } \\
\text { (suburbano) }\end{array}$ & $\begin{array}{l}\text { fórmico, acético, pirúvico, glioxílico, } \\
\text { oxálico, succínico, malônico }\end{array}$ & $\begin{array}{c}160,8 ; 194,0 ; 59,1 ; 44,0 \\
186,1 ; 118,6 ; 84,4\end{array}$ & 22 \\
\hline $\begin{array}{l}\text { Canto, Japão } \\
\text { (urbano) }\end{array}$ & $\begin{array}{l}\text { oxálico, malônico, succínico, } \\
\text { glutárico, adípico, ftálico }\end{array}$ & $\begin{array}{l}7,8 ; 23,3 ; 47,1 \\
21,0 ; 11,3 ; 38,3\end{array}$ & 17 \\
\hline $\begin{array}{l}\text { Tóquio, Japão } \\
\text { (urbano) }\end{array}$ & $\begin{array}{l}\text { oxálico, malônico, metilmalônico, } \\
\text { maleico, succínico, metilsuccínico, } \\
\text { fumárico, metilmaleico, málico, } \\
\text { glutárico, adípico, pimélico, subárico, } \\
\text { azeláico, sebáico, ftálico }\end{array}$ & $\begin{array}{c}270 ; 55 ; 2,5 ; 5,6 ; 37 ; 5,1 \\
3,7 ; 3,8 ; 23 ; 11 ; 16 ; 5,3 ; 8,4 \\
23 ; 4,8 ; 15\end{array}$ & 24 \\
\hline $\begin{array}{l}\text { Creta, Grécia } \\
\text { (urbano) }\end{array}$ & $\begin{array}{l}w \text { - oxo-carboxílicos }\left(\mathrm{C}_{8}-\mathrm{C}_{9}\right) \\
a, w \text { - dicarboxílicos }\left(\mathrm{C}_{6}-\mathrm{C}_{27}\right)\end{array}$ & 0,$54 ; 0,75$ & 35 \\
\hline São Paulo, Brasil (urbano) & fórmico, acético, glicólico, oxálico & $350 ; 150 ; 110 ; 140$ & 75 \\
\hline Califórnia, EUA (urbano) & oxálico & 0,38 & 84 \\
\hline
\end{tabular}

a - média das concentrações

de reações químicas. Na Figura 1 pode ser observado um esquema geral que representa os processos de formação e as emissões diretas dos ácidos carboxílicos. As fontes antropogênicas têm sido as responsáveis pela emissão dos ácidos acético, fórmico, ceto-ácidos e dicarboxílicos, tais como oxálico, succínico e glutárico ${ }^{40}$. Por outro lado, as fontes biogênicas emitem ácidos graxos e também ácidos fórmico e acético ${ }^{41}$.

\section{Fontes Antropogênicas}

As atividades antropogênicas que dão origem aos ácidos carboxílicos na atmosfera englobam os processos de combustão, tais como a queima de combustíveis fósseis, a queima de vegetação e a incineração de matéria orgânica. Estes processos são responsáveis pela presença de ácidos orgânicos na atmosfera, os quais são encontrados em quantidades significativas na fase gasosa e em quantidades menores no aerossol atmosférico ${ }^{18}$.

Em ambientes urbanos, a queima de combustíveis por motores veiculares é uma fonte de emissão predominante de ácidos carboxílicos na atmosfera. De um modo geral, a emissão veicular libera para a atmosfera diferentes ácidos orgânicos sendo que $78 \%$ corresponde aos ácidos acético e fórmico, $15 \%$ aos outros monocarboxílicos alifáticos, $5 \%$ aos aromáticos e $2 \%$ aos dicarboxílicos alifáticos ${ }^{15,21,42}$. Apesar da taxa de emissão das espécies ser dependente do número e da idade dos veículos, estudos realizados mostram dados de emissão diária de 1,0 a 13,0 ton/mês e 3,0 a 15,0 ton/mês para os ácidos acético e fórmico, respectivamente ${ }^{13}$.

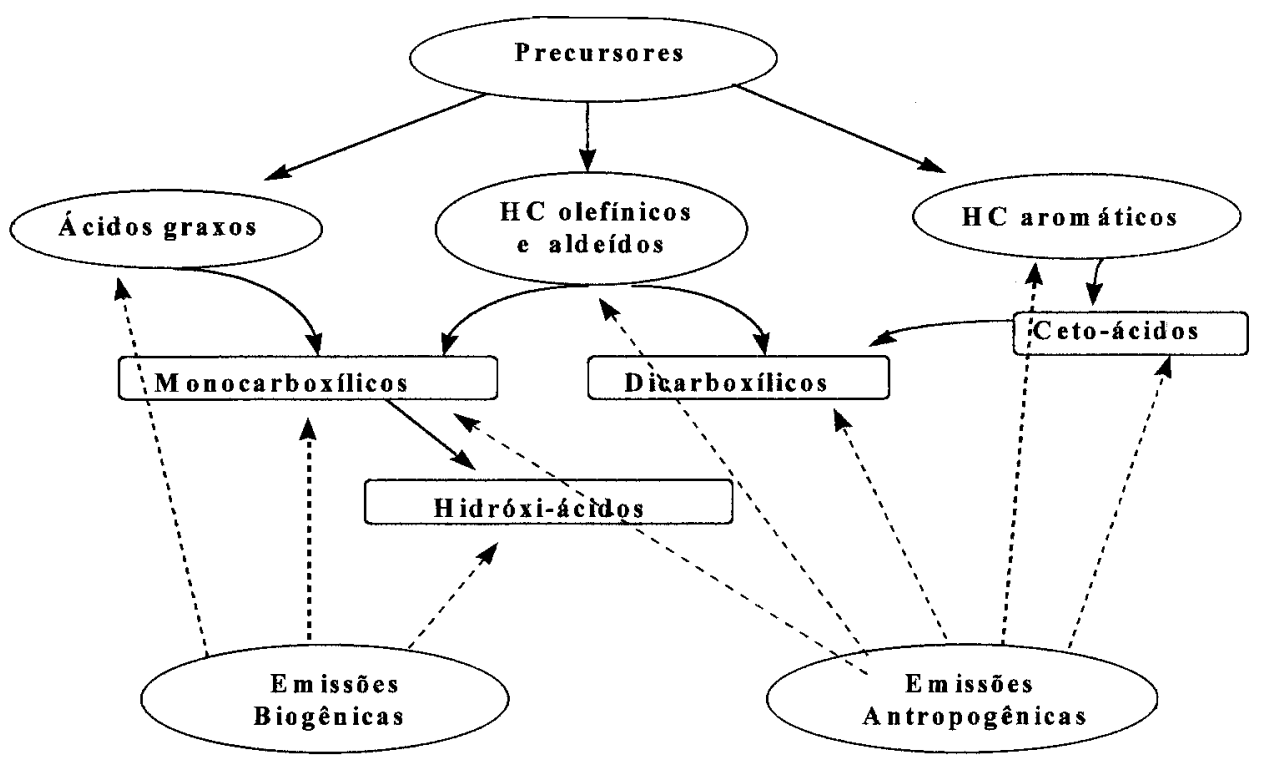

Figura 1. Origens das principais classes de ácidos carboxílicos encontrados na atmosfera. 
$\mathrm{Na}$ atmosfera de ambientes rurais e florestais, a principal fonte dos ácidos acético e fórmico são as queimadas freqüentes que ocorrem durante o período de seca ${ }^{11}$. Estudos realizados nestas regiões têm mostrado que as concentrações destes ácidos são extremamente elevadas atingindo valores de 75 a 150 ppbv para fórmico e 750 a 1250 ppbv para acético. Estas concentrações são normalmente dez vezes superiores às concentrações encontradas em regiões urbanas ${ }^{3,14}$.

\section{Fontes Naturais}

As fontes naturais que podem contribuir para o aumento dos níveis de ácidos orgânicos na atmosfera são aquelas provenientes de processos de biossíntese por bactérias, fungos, insetos e plantas.

Em áreas tropicais, Gradel e Eisner ${ }^{43}$ observaram a emissão do ácido fórmico pelas formigas (Componotus floridanus). Apesar da contribuição desta fonte ser pouco importante para a compreensão da origem do ácido fórmico na atmosfera, foi observado um impacto ambiental nas regiões próximas ao habitat destes insetos.

As fontes naturais de ácidos orgânicos mais relevantes para a atmosfera são o solo e a vegetação ${ }^{18,31,45,46}$. Os produtos do metabolismo de microorganismos, por exemplo bactérias, e plantas são os responsáveis pela ocorrência de ácidos orgâni$\cos$ no solo ${ }^{45}$. Em regiões suburbanas e florestais, o impacto ambiental de ácidos orgânicos por esta fonte de emissão tem despertado grande interesse ${ }^{46}$. No entanto, a contribuição do solo como fonte destas espécies na atmosfera não está ainda bem esclarecida e estudos mais detalhados são necessários.

Por outro lado, os processos de biossíntese de plantas que vem sendo estudados há mais de uma década, são provavelmente a principal fonte dos ácidos carboxílicos em atmosfera de regiões tropicais ${ }^{31,39}$. A contribuição destas fontes em regiões temperadas, entretanto, não parece ser tão relevante quanto nos trópicos. Embora a emissão seja maior em áreas florestais, estudos têm mostrado que a vegetação contribui com 25 a $45 \%$ dos ácidos carboxílicos presentes na atmosfera global ${ }^{3}$.

Dentre os ácidos orgânicos emitidos pela vegetação, os mais abundantes são os ácidos fórmico, acético e pirúvico ${ }^{18,47}$. Estima-se que o fluxo de emissão destes ácidos em regiões tropicais, como a floresta Amazônica, seja de $9,8 \times 10^{9}, 4,6 \times 10^{9}$, $9,8 \times 10^{8}$ moléculas $/ \mathrm{cm}^{2} . \mathrm{s}^{1}$ para os ácidos fórmico, acético e pirúvico, respectivamente ${ }^{18}$.

As partículas naturais da vegetação, ou seja, o pólen, também são fontes de ácidos carboxílicos no aerossol atmosférico. Tais partículas contem concentrações substanciais de sais de acetato $(17,6 \mu \mathrm{mol} / \mathrm{g})$ e formiato $(1,0 \mu \mathrm{mol} / \mathrm{g})^{18}$.

\section{Formação in situ}

Os mecanismos das reações químicas que conduzem à formação de ácidos carboxílicos na fase gasosa ou na superfície do aerossol têm sido estudados por Atkinson e Carter ${ }^{48,49}$. As reações envolvendo os radicais peroxi-orgânicos e a oxidação de olefinas, aldeídos, hidrocarbonetos aromáticos e ácidos difuncionais são os principais processos químicos responsáveis pela formação in situ dos ácidos carboxílicos na atmosfera ${ }^{50}$.

\section{Oxidação de Alcenos}

A grande maioria dos alcenos presentes na atmosfera sofre oxidação por reação com ozônio. Esta reação, representada ${ }^{53}$ a seguir, ocorre pela adição eletrofílica do ozônio na dupla ligação C-C formando a ozonida (RCOOOCR) que se decompõe rapidamente em compostos carbonílicos (RCO) e birradicais $\left(\mathrm{RCOO}^{\circ}\right)^{49,50-53}$.

Os birradicais de alta energia podem se decompor formando compostos estáveis $\left(\mathrm{CO}_{2}, \mathrm{CO}, \mathrm{H}_{2} \mathrm{O}\right)$ e novos radicais $\left(\mathrm{OH}^{\circ}\right.$ e $\mathrm{HO}_{2}{ }_{2}$ ) ou ainda podem sofrer colisões moleculares formando o birradical estável ${ }^{51}$. Aproximadamente $40 \%$ do birradical excitado, $\mathrm{CH}_{2} \mathrm{OO}^{*}$, pode se tornar estável (rota A). A estabilidade do birradical está diretamente relacionada com o tamanho da cadeia carbônica do alceno precursor ${ }^{52}$.

$\mathrm{O}$ birradical estável pode reagir com $\mathrm{SO}_{2}, \mathrm{NO}, \mathrm{CO}, \mathrm{NO}_{2}$ e $\mathrm{H}_{2} \mathrm{O}$, conforme as equações ${ }^{50}$ :
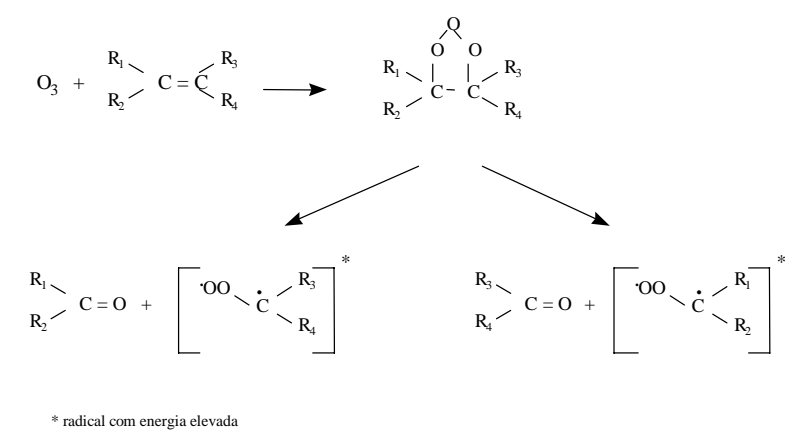

$\mathrm{RC}^{\bullet}\left(\mathrm{OO}^{*}\right) \mathrm{R}^{\prime}+\mathrm{SO}_{2} \rightarrow \mathrm{RC}(\mathrm{O}) \mathrm{R}^{\prime}+\mathrm{SO}_{3}$

( $\mathrm{k}=7,0 \times 10^{-14} \mathrm{~cm}^{3} /$ moléculas.s)

$\mathrm{RC}^{\bullet}\left(\mathrm{OO}^{\circ}\right) \mathrm{R}^{\prime}+\mathrm{NO} \rightarrow \mathrm{RC}(\mathrm{O}) \mathrm{R}^{\prime}+\mathrm{NO}_{2}$

( $\mathrm{k}=1,0 \times 10^{-14} \mathrm{~cm}^{3} /$ moléculas.s)

$\mathrm{RC}^{\bullet}\left(\mathrm{OO}^{\circ}\right) \mathrm{R}^{\prime}+\mathrm{CO} \rightarrow \mathrm{RC}(\mathrm{O}) \mathrm{R}^{\prime}+\mathrm{CO}_{2}$

$\left(\mathrm{k}=1,2 \times 10^{-15} \mathrm{~cm}^{3} /\right.$ moléculas.s $)$

$\mathrm{RC}^{\bullet}\left(\mathrm{OO}^{\bullet}\right) \mathrm{R}^{\prime}+\mathrm{NO}_{2} \rightarrow \mathrm{RC}(\mathrm{O}) \mathrm{R}^{\prime}+\mathrm{NO}_{3}$

( $\mathrm{k}=1,0 \times 10^{-15} \mathrm{~cm}^{3} /$ moléculas.s)

$\mathrm{RC}^{\bullet}\left(\mathrm{OO}^{\circ}\right) \mathrm{R}^{\prime}+\mathrm{H}_{2} \mathrm{O} \rightarrow \mathrm{RC}(\mathrm{O}) \mathrm{R}^{\prime}+\mathrm{H}_{2} \mathrm{O}_{2}$

( $\mathrm{k}=6,0 \times 10^{-18} \mathrm{~cm}^{3} /$ moléculas.s)

Quando existir um átomo de hidrogênio no carbono- $\alpha$, o birradical pode reagir com a molécula de água produzindo o ácido orgânico correspondente:

$\mathrm{RC}^{\bullet}\left(\mathrm{OO}^{*}\right) \mathrm{H}+\mathrm{H}_{2} \mathrm{O} \rightarrow \mathrm{RC}(\mathrm{O}) \mathrm{OH}+\mathrm{H}_{2} \mathrm{O}$
$\left(\mathrm{k}=1,0 \times 10^{-17} \mathrm{~cm}^{3} /\right.$ moléculas.s $)$

Uma outra rota de formação dos ácidos orgânicos à partir da ozonólise dos alcenos é a isomerização do birradical (rota B) sendo que aproximadamente $6 \%$ do birradical formado pode sofrer isomerização para formar o ácido orgânico.

De um modo geral, a extensão destas reações está relacionada com a concentração das espécies envolvidas e a cinética das reações ${ }^{48,49,50}$.

Deve-se observar que os alcenos também reagem com os radicais $\mathrm{OH}^{*}$ e $\mathrm{NO}_{3}{ }^{*}$. Estas duas reações competem com as reações entre os alcenos e o ozônio porém não formam os ácidos carboxílicos. Assim, a contribuição relativa da produção de ácidos orgânicos por reação de ozônio com olefinas depende das concentrações atmosféricas de $\mathrm{O}_{3}, \mathrm{OH}^{*}, \mathrm{NO}_{3}{ }^{\circ}$ e da cinética das reações ${ }^{13}$.

Os radicais $\mathrm{OH}^{\circ}$, assim como o ozônio, são formados durante o dia e as suas concentrações diminuem drasticamente à noite. Em contrapartida, os radicais $\mathrm{NO}_{3}{ }^{\bullet}$ sofrem fotólise e são considerados oxidantes importantes à noite quando as suas concentrações tendem a crescer ${ }^{48,50}$.

Estudos cinéticos têm mostrado que durante o dia há um aumento das reações ozônio-olefinas em relação as reações $\mathrm{OH}$ olefinas, de acordo com o aumento da reatividade do alceno. As olefinas menos reativas, como etileno e butadieno, e as mais reativas, como 2-buteno e 2-penteno, produzem uma taxa de 22-33\% e 85-97\% de ácidos orgânicos, respectivamente (Tabela 4). À noite, entretanto, os radicais $\mathrm{NO}_{3}{ }^{\circ}$ reagem rapidamente com as olefinas mais reativas e o ozônio com as espécies menos reativas, como por exemplo, o etileno ${ }^{13,50}$. 
Tabela 4. Ácidos orgânicos produzidos pela ozonólise de olefinas e as respectivas constantes de velocidade das reações ${ }^{3}$

\begin{tabular}{lcc}
\hline Olefina & Ácido orgânico & $\begin{array}{c}\mathrm{k}^{* *} \cdot 10^{18} \\
\left(\mathrm{~cm}^{3} / \text { moléculas.s }\right)\end{array}$ \\
\hline etileno & fórmico & 1,70 \\
propeno & fórmico e acético & 11,3 \\
1-buteno & fórmico & 11,0 \\
cis 2-buteno & acético & 130 \\
trans 2-buteno & acético & 200 \\
isobuteno & fórmico & 12,1 \\
2-metil-1-buteno & fórmico & 10,0 \\
2-metil-2-buteno & acético & 423 \\
1,3-butadieno & fórmico & 7,50 \\
2-metil-1,3-butadieno & fórmico, pirúvico & 14,3 \\
& e metacrilíco & \\
1-penteno & fórmico e $n$-butírico \\
cis 2-penteno & acético e propiônico \\
trans 2-penteno & acético e propiônico \\
3-metil-1penteno & fórmico e isovalérico \\
hexeno & fórmico \\
ciclohexeno & fórmico, adípico*, \\
& glutárico*, \\
& 6-oxo-hexanóico*, \\
& 5-oxo-pentanóico* & 10,7 \\
\end{tabular}

*Conversão gás-partícula imediata; $* * \mathrm{k}=$ constante de velocidade de reação entre a olefina e o ozônio

A taxa de produção de ácidos orgânicos pela ozonólise de olefinas tem sido estimada para os períodos diurno e noturno. Durante o dia estima-se que 25 ton/dia de ácido fórmico e 10,1 ton/dia de ácido acético são produzidas in situ por reações ozônio-olefinas e durante à noite 34,5 e 4,3 ton/dia para fórmico e acético, respectivamente ${ }^{13}$.

As reações de ozonólise das olefinas são provavelmente os processos de formação in situ dos ácidos orgânicos mais importantes na atmosfera. A maioria das olefinas presentes na atmosfera é precursora dos ácidos fórmico e acético ${ }^{54,55}$. O isopreno (2-metil-1,3-butadieno) é precursor dos ácidos fórmico, pirúvico e metacrílico. Por outro lado, o penteno, além de produzir os ácidos fórmico e acético, também conduz à formação dos ácidos propiônico, butírico e isovalérico ${ }^{3}$. Já as olefinas cíclicas e as diolefinas podem gerar os oxo- e di-carboxílicos, como por exemplo os ácidos succínico, glutárico, adípico, 5-oxo-pentanóico e 6-oxo-hexanóico ${ }^{2,35,37,56}$.

\section{Oxidação de Hidrocarbonetos Aromáticos}

Os hidrocarbonetos aromáticos presentes na atmosfera podem ser oxidados através da adição de radicais $\mathrm{OH}^{*}$ no anel aromático e formação de novas espécies radicalares que levam à geração de vários compostos oxigenados ${ }^{3}$.

Embora os mecanismos destas reações sejam complexos, muitos estudos demonstram que a oxidação de anéis aromáticos produz vários compostos intermediários que participam de reações com $\mathrm{O}_{3}$ e radicais $\mathrm{OH}^{*}$ resultando em fenóis, aldeídos (glioxal, metilglioxal) e ácidos orgânicos (pirúvico, oxálico, maleico e metil-maleico e benzóico $)^{30,57,58}$, conforme o esquema geral representado abaixo.

\section{Oxidação de compostos carbonílicos}

Os compostos carbonílicos, como cetonas, aldeídos e dicarbonílicos, são reativos e podem sofrer fotólise e reagir com radicais livres $\left(\mathrm{OH}^{\circ}, \mathrm{NO}_{3}{ }^{\circ}, \mathrm{HO}_{2}{ }^{\circ}\right)$ e $\mathrm{O}_{3}$. As reações que envolvem aldeídos com radicais livres $\left(\mathrm{HO}_{2}{ }^{\circ}\right.$ e $\left.\mathrm{OH}^{\circ}\right)$, assim como compostos carbonílicos insaturados com $\mathrm{O}_{3}$ conduzem à formação de ácidos orgânicos.

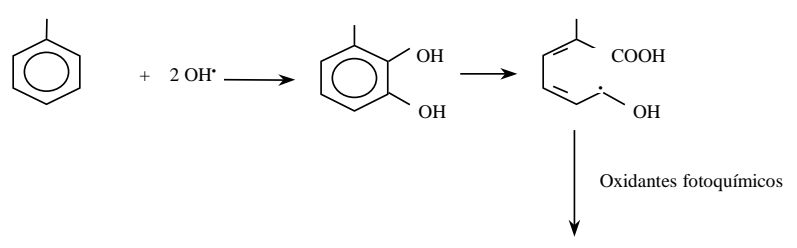

$\mathrm{RCOOH}+\mathrm{R}^{\prime} \mathrm{COH}$

Apesar das reações de oxidação de compostos , Jonílicos não contribuírem de forma significativa para os processos de formação in situ dos ácidos orgânicos, a literatura tem apontado que formaldeído e metil-vinil-cetona são precursores importantes dos ácidos fórmico e pirúvico, respectivamente. Jacob e Wosfy ${ }^{59}$, Veyret et al. ${ }^{60}$, McElroy e Waygood ${ }^{61}$ e Chien et $a l .{ }^{62}$ estudaram os possíveis mecanismos destas reações. Veyret et al. ${ }^{60}$ propuseram que o ácido fórmico pode ser formado na fase gasosa através da reação entre formaldeído e radical $\mathrm{HO}_{2}{ }^{\circ}$ :

$\mathrm{HCHO}+\mathrm{HO}_{2}{ }^{\bullet} \rightarrow \mathrm{HOCH}_{2} \mathrm{O}_{2}{ }^{\cdot}$

$\mathrm{HOCH}_{2} \mathrm{O}_{2}{ }^{\bullet}+\mathrm{NO} \rightarrow \mathrm{NO}_{2}+\mathrm{OCH}_{2} \mathrm{OH}^{\bullet}$

$\mathrm{OCH}_{2} \mathrm{OH}^{\bullet}+\mathrm{O}_{2} \rightarrow \mathrm{HO}_{2}^{\cdot}+\mathrm{HCOOH}$

Conforme Chien et al. ${ }^{62}$, a ozonólise de metil-vinil-cetona produz um epóxido que se decompõe em dois biradicais: um substituído e outro não substituído. Por outro lado, o biradical substituído reage prontamente com a água formando o ácido pirúvico ${ }^{59}$ :

$$
\begin{aligned}
& \mathrm{CH}_{2} \mathrm{CHC}(\mathrm{O}) \mathrm{CH}_{3}+\mathrm{O}_{3} \rightarrow \mathrm{CH}_{3} \mathrm{C}(\mathrm{O}) \mathrm{CHOOOCH}_{2} \\
& \mathrm{CH}_{3} \mathrm{C}(\mathrm{O}) \mathrm{CHOOOCH}_{2} \rightarrow \mathrm{CH}_{3} \mathrm{C}(\mathrm{O}) \mathrm{C}^{\bullet} \mathrm{HOO}^{\bullet}+\mathrm{HC}(\mathrm{O}) \mathrm{H} \\
& \mathrm{CH}_{3} \mathrm{C}(\mathrm{O}) \mathrm{C}^{\bullet} \mathrm{HOO}^{\bullet}+\mathrm{H}_{2} \mathrm{O} \rightarrow \mathrm{CH}_{3} \mathrm{C}(\mathrm{O}) \mathrm{COOH}+\mathrm{H}_{2} \mathrm{O}
\end{aligned}
$$

Outros ácidos orgânicos também podem ser gerados por oxidação de compostos carbonílicos. Dentre eles, destacam-se os ácidos oxálico e glioxílico que podem ser produtos de oxidação do glioxal e metil glioxal, respectivamente ${ }^{36}$.

\section{Oxidação de ácidos difuncionais}

Os ácidos graxos insaturados são considerados precursores dos ácidos dicarboxílicos e oxo-carboxílicos constituídos de 8 a 10 átomos de carbono ${ }^{35}$. Tais compostos produzem os ácidos orgânicos através da ozonólise de olefinas conforme discutido anteriormente.

No entanto, os ácidos dicarboxílicos e oxo-carboxílicos podem sofrer oxidação dando origem a outros ácidos orgânicos. Embora os mecanismos destas reações ainda não estão bem elucidados, alguns autores consideram os ácidos succínico, malônico e glioxílico, os precursores dos ácidos maleico, cetomalônico e oxálico, respectivamente. Também, os hidróxi-ácidos e o ácido pirúvico são considerados precursores potenciais do ácido oxálico ${ }^{34,36}$.

\section{Reações envolvendo radicais peroxi- orgânicos}

Os radicais alquilas $\left(\mathrm{RO}_{2}{ }^{\circ}\right)$ e acetil peroxilas $\left(\mathrm{R}(\mathrm{O}) \mathrm{O}_{2}{ }^{\circ}\right)$ são produzidos na atmosfera através da fotodegradação de compostos orgânicos voláteis. As fontes mais relevantes destes radicais são a fotólise parcial de compostos oxigenados e suas reações com radicais livres $\left(\mathrm{OH}^{*}\right.$ e $\left.\mathrm{NO}_{3}{ }^{\circ}\right)$ seguida pela adição de oxigênio ${ }^{63}$.

$\mathrm{RCOR}+h v+2 \mathrm{O}_{2} \rightarrow \mathrm{RCO}\left(\mathrm{OO}^{*}\right)+\mathrm{R}\left(\mathrm{OO}^{*}\right)$

$\mathrm{RCHO}+\mathrm{OH}^{\bullet}+\mathrm{O}_{2} \rightarrow \mathrm{RCO}\left(\mathrm{OO}^{*}\right)+\mathrm{H}_{2} \mathrm{O}$

$\mathrm{RCHO}+\mathrm{NO}_{3}{ }^{\bullet}+\mathrm{O}_{2} \rightarrow \mathrm{RCO}\left(\mathrm{OO}^{\circ}\right)+\mathrm{HNO}_{3}$ 
Os radicais peroxilas reagem com outros radicais $\left(\mathrm{HO}_{2}{ }^{\circ}\right)$ e com espécies inorgânicas $\left(\mathrm{NO}, \mathrm{NO}_{2}\right)$. As reações destes radicais com $\mathrm{NO}_{\mathrm{x}}\left(\mathrm{NO}_{2}+\mathrm{NO}\right)$ produzem os nitratos de peroxiacetila $\left(\mathrm{RCO}\left(\mathrm{OONO}_{2}\right)\right.$ e outros nitratos orgânicos $\left(\mathrm{RCOONO}_{2}\right)$. Por outro lado, os ácidos orgânicos podem ser formados quando os radicais peroxilas interagem entre si ou reagem com radicais $\mathrm{HO}_{2}{ }^{\circ}$, conforme as seguintes as equações ${ }^{49}$ :

$$
\begin{aligned}
& \mathrm{RCO}\left(\mathrm{OO}^{*}\right)+\mathrm{R}^{\prime} \mathrm{CH}\left(\mathrm{OO}^{*}\right) \rightarrow \mathrm{R}(\mathrm{COOH})+\mathrm{R}^{\prime} \mathrm{CO}+\mathrm{O}_{2} \\
& \mathrm{RCO}\left(\mathrm{OO}^{*}\right)+\mathrm{HO}_{2}{ }^{\circ} \rightarrow \mathrm{R}(\mathrm{COOH})+\mathrm{O}_{3} \\
& \mathrm{RC}\left(\mathrm{OO}^{*}\right)+\mathrm{HO}_{2}{ }^{\cdot} \rightarrow \mathrm{R}(\mathrm{COOH})+\mathrm{O}_{2}
\end{aligned}
$$

Do ponto de vista cinético, tais reações são favorecidas em baixas concentrações de $\mathrm{NO}_{\mathrm{x}}$. Assim, para a formação de ácidos orgânicos em ambientes florestais, rurais e marinho, em que a demanda de $\mathrm{NO}_{\mathrm{x}}$ é pequena, estas reações são significativas. Estudos realizados por Mandronick e Calvert ${ }^{63} \mathrm{em}$ atmosfera simulada indicaram que os ácidos acético, glicólico e pirúvico são os principais produtos destas reações. O ácido fórmico não pode ser formado por estes processos devido à ausência do radical $\mathrm{HCO}\left(\mathrm{OO}^{*}\right)$ que deveria ser formado pela reação de radical formila $\left(\mathrm{HCO}^{\circ}\right)$ com $\mathrm{O}_{2}$, o qual produz $\mathrm{HO}_{2}{ }^{*}$ e $\mathrm{CO}$ ao invés de $\mathrm{HCO}\left(\mathrm{OO}^{\circ}\right)$.

A contribuição dos ácidos carboxílicos formados pelas reações com radicais peroxi em atmosfera urbana é ainda pouco conhecida. Sabe-se que em concentrações baixas de $\mathrm{NO}_{\mathrm{x}}$ os radicais peroxilas reagem entre si gerando ácidos orgânicos. Este caminho de formação dos ácidos orgânicos ocorre preferencialmente à noite quando os níveis de $\mathrm{NO}_{\mathrm{x}}$, são menores.

\section{PROCESSOS DE REMOÇÃO DOS ÁCIDOS CARBOXÍlICOS ATMOSFÉRICOS}

Os ceto-ácidos são os únicos ácidos orgânicos removidos da atmosfera através de reações na fase gasosa. Uma vez presentes na atmosfera, estes ácidos são estáveis por poucas horas, decompondo-se rapidamente por fotólise ${ }^{64}$.

$\mathrm{CH}_{3} \mathrm{C}(\mathrm{O}) \mathrm{COOH}+h v \rightarrow \mathrm{CH}_{3} \mathrm{CHO}+\mathrm{CO}_{2}$ $\left(\mathrm{k}=1,62.10^{-2} \mathrm{~min}^{-1}\right)$

Os ácidos carboxílicos, exceto os ceto-ácidos, podem ser removidos da atmosfera por reações com radicais $\mathrm{OH}$. No entanto, este processo de remoção é extremamente lento. Os valores das constantes de velocidade de reação de $\mathrm{OH}$-ácido orgânico são da ordem de $10^{-12} \cdot \mathrm{cm}^{3}$. moléculas ${ }^{-1} \cdot \mathrm{s}^{-1}$ Esta constante corresponde a um tempo de vida de várias semanas ou aproximadamente 50 dias $^{65}$, o que representa um-processo de remoção ineficiente. Por exemplo, a taxa de remoção do ácido fórmico pela reação com $\mathrm{OH}$ é igual a $0,017 \mathrm{ppb} / \mathrm{h}$, à $10 \mathrm{ppb}$ de ácido fórmico e $10^{6}$ moléculas $/ \mathrm{cm}^{3} \mathrm{de} \mathrm{OH}$. Considerando um transporte de massa de 12 horas e a taxa de remoção do ácido fórmico, pode-se estimar que apenas $0,2 \mathrm{ppb}$ do ácido é removido da atmosfera ${ }^{13}$.

Os principais mecanismos de remoção dos ácidos carboxílicos são baseados na deposição seca e úmida. A deposição seca envolve a sedimentação de partículas e a deposição úmida está associada com a remoção de gases e partículas por gotas de água nas nuvens (rainout) e nas chuvas (washout). De um modo geral, quando a remoção é por deposição, o tempo de residência dos ácidos carboxílicos na atmosfera é comparativamente pequeno podendo variar desde algumas horas até alguns poucos dias ${ }^{3}$.

A remoção destas espécies está diretamente relacionada com o grau de partição entre as espécies gasosas e a água presente no aerossol, nas nuvens e nas chuvas ${ }^{66}$. A partição gás/líquido definida pela constante de Henry para os diversos ácidos carboxílicos está apresentada na Tabela 5. A distribuição das espécies nas fases gasosa e líquida depende da temperatura, umidade relativa, $\mathrm{pH}$ do meio e concentração de sais dissolvidos ${ }^{1,23}$.

Tabela 5. Constante da Lei de Henry $\left(\mathrm{k}_{\mathrm{H}}\right)$ para alguns ácidos $\operatorname{orgânicos}^{1}$.

\begin{tabular}{lc}
\hline Ácido & $\begin{array}{c}\mathrm{k}_{\mathrm{H}} 10^{3}, \\
\left(\mathrm{~mol}_{\mathrm{kg}}^{-1} \cdot \mathrm{atm}^{-1}\right), 298 \mathrm{~K}\end{array}$ \\
\hline fórmico & 5,530 \\
acético & 5,502 \\
propiônico & 5,713 \\
butírico & 4,727 \\
valérico & 2,232 \\
capróico & 1,388 \\
pirúvico & 311,0 \\
\hline
\end{tabular}

Os ácidos orgânicos com pKa na faixa de 3,5 e 5 interagem facilmente com a fase aquosa sendo removidos da atmosfera por processos de deposição úmida devido ao alto grau de dissociação e elevada solubilidade ${ }^{1}$. Estima-se, entretanto, que $90 \%$ dos ácidos orgânicos são removidos da atmosfera por processos de deposição seca. A velocidade e a taxa de deposição para os ácidos foram estimadas como sendo $1 \mathrm{~cm} / \mathrm{s}$ e 50 ton/dia, respectivamente ${ }^{21}$.

\section{CONCLUSÕES}

Apesar dos vários estudos sobre a formação, emissão e remoção dos ácidos carboxílicos na atmosfera, muitas investigações ainda se fazem necessárias para um melhor entendimento da ocorrência destas espécies, bem como de suas fontes de emissão e processos de remoção da atmosfera. Neste contexto, a diversidade das fontes, a variabilidade temporal e geográfica e a complexidade das reações fotoquímicas envolvidas na formação destes compostos são aspectos fundamentais a serem investigados. Para tal, trabalhos futuros sobre ácidos carboxílicos na atmosfera deverão ser dirigidos no sentido de especiar os ácidos carboxílicos emitidos na exaustão de motores veiculares e na queima da biomassa e da vegetação; avaliar a influência destas espécies na acidez atmosférica e suas implicações no processo de corrosão atmosférica; compreender os processos de remoção dos ácidos orgânicos na atmosfera de regiões urbanas e florestais.

Assim como os ácidos carboxílicos, outras classes de compostos orgânicos participam do smog fotoquímico e um maior número de estudos relacionados com este processo se faz necessário para elucidar melhor a química da atmosfera. Sabe-se que os ácidos carboxílicos participam ativamente das reações químicas envolvidas no processo de $\operatorname{smog}$ fotoquímico e, de um modo geral, os compostos orgânicos voláteis promovem a formação de poluentes secundários, entre outros, os oxidantes fotoquímicos nocivos à saúde humana.

\section{AGRADECIMENTOS}

Os autores agradecem à FAPESP pelo apoio financeiro à pesquisa (projeto temático processo $\mathrm{n}^{\circ}$ 96/01403-4) e pela bolsa de pós-doutorado concedida à Silvia R. Souza (processo n ${ }^{\circ}$ 98/ 11078-9).

\section{REFERÊNCIAS}

1. Khan, I.; Brimblecombe, P.; Clegg, S. L.; J. Atmos. Chem. 1995, 22, 285.

2. Ludwig, J.; Klemm, O.; Tellus, Ser. B 1988, 40, 340.

3. Chebbi, A.; Carlier P.; Atmos. Environ., Part A 1996, 24, 4233. 
4. Keene, W. C.; Galloway, J. N.; Atmos. Environ., Part A 1984, 18, 2491

5. Galloway, N. J.; Likens, G. E.; Keene, W. C.; Miller, J. M.; J. Geophys. Res. 1982, 87, 8771.

6. Gradel, T. E.; McCrory-Joy, C.; Franey, J. P.; J. Electrochem. Soc. 1986, 33, 452.

7. Vilca-Meléndez, H.; Souza, S. R.; Carvalho, L. R. F.; Aoki, I. V.; Anais do II Colóquio de Corrosão Atmosférica, IPT, São Paulo, SP, 1994.

8. Palassis, J.; J. Am. Ind. Assoc. 1978, 39, 731.

9. Shuetzle D.; Cronn D.; Crittenden L.; Charlson, R. J.; Environ. Sci. Technol. 1975, 9, 838.

10. Grosjean, D.; Cauwenberghe, K. V.; Schmid, J. P.; Kelly, P. E.; Pitts, J. N.; Environ. Sci. Technol. 1978, 12, 313

11. Talbot, R. W.; Beecher, K. M.; Harriss, R. C.; Coffer, W. R.; J. Geophys. Res. 1988, 93, 1638.

12. Hartmann, W. R.; Andreae, M. O.; Helas, G.; Atmos. Environ. 1989, 23, 1531.

13. Grosjean, D.; Atmos. Environ. Part A 1992, 26, 3279.

14. Helas, G.; Bingemer, H.; Andreae, M. O.; J. Geophys. Res. 1992, 97, 6187.

15. Kawamura, K.; Ng, L.; Kaplan, I. R.; Environ. Sci. Technol. 1985, 19, 1082.

16. Satsumabayashi, H.; Kurita, H.; Yokouchi, Y.; Ueda, H.; Tellus, Ser. B 1989, 41, 219.

17. Andreae, M. O.; Talbolt, R. W.; Li, S. M.; J. Geophys. Res. 1987, 92, 6635.

18. Talbot, R. W.; Andreae, M. O.; Berresheim, H.; Jacob, D. J.; Beecher, K. M.; J. Geophys. Res. 1990, 95, 16799.

19. Klemm, O.; Talbolt, R. W.; Fitzgerald, D. R.; Klemm, K. I.; Lefer, B. L.; J. Geophys. Res. 1994, 99, 1687.

20. Puxbaum, H.; Rosenberg, C.; Gregori, M.; Lanzerstorfer, C.; Ober, E; Winwarter, W.; Atmos. Environ. 1988, 22, 2841.

21. Grosjean, D.; Environ. Sci. Technol. 1989, 23, 1506.

22. Khwaja, A. H.; Atmos. Environ. 1995, 29, 127.

23. Facchini, M. C.; Fuzzi, S.; Lind, J. A.; FierlingerOberlinninger, H.; Kalina, M.; Puxbaum, H.; Winiwarter, W.; Arends, B. G.; Wobrock, W.; Jaeschke, W.; Berner, A.; Kruisz, C.; Tellus, Ser. B 1992, 44, 533.

24. Kawamura, K.; Kaplan, I. R.; Environ. Sci. Technol. 1983, 17, 497.

25. Guiang, S. F.; Sagar, V.; Krupa, V.; Pratt, G. C.; Atmos. Environ. 1984, 18, 1677.

26. Chapman, E. G.; Sklarew, D. S.; Flickinger, J. S.; Atmos. Environ. 1986, 20, 1717.

27. Andreae, M. O.; Talbolt, R. W.; Beresheim, H.; Beecher, K. M.; J. Geophys. Res. 1990, 95, 16987.

28. Willey, J. D.; Wilson, C. A.; J. Atmos. Chem. 1993,16, 123

29. Sempéré, R.; Kawamura, K.; Atmos. Environ. 1996, 30, 1609.

30. Kawamura, K.; Steinberg, S.; Kaplan, I. C.; Atmos. Environ. 1996, 30, 1035.

31. Keene, W. C.; Galloway, J. N.; Tellus, Ser. B 1988, 40, 332.

32. Satsumabayashi, H.; Kurita, H.; Yokouchi, Y.; Ueda, H.; Atmos. Environ., Part A 1990, 24, 1443.

33. Sempéré, R.; Kawamura, K.; Atmos. Environ. 1994, $28,449$.

34. Kawamura, K. e Ikushima, K. Environ. Sci. Technol. 1993, 27, 2227.

35. Stephanou, E. G.; Stratigakis, N.; Environ. Sci. Technol. 1993, 27, 1403.

36. Kawamura, K.; Kasube, H.; Barrie L.; Atmos. Environ. 1996, 30, 1709 .

37. Satsumabayashi, H.; Kurita, H.; Chang, Y.; Carmichael, G.; Ueda, H.; Atmos. Environ. 1995, 29, 255.

38. Meng, Z.; Seinfeld, J. H.; Saxena, P.; Aerosol Sci. Technol. 1995, 23, 561.

39. Andreae, M. O.; Talbolt, R. W.; Andreae, T. W.; Harriss, R. C.; J. Geophys. Res. 1988, 93, 1616.

40. Lefer, B. L.; Talbolt, R. W.; Harris, C. R.; Bradshaw, S. T.; Sandholm, S. T.; Olson, J. O.; Sachse, G. W.; Collins, J.;
Shipham, M. A.; Blake, D. R.; Klemm, K. I.; Klemm, O.; Gorzelska, K.; Barrick, J.; Atmos. Environ. 1988, 22, 1011

41. Talbolt, R. W.; Mosher, B. W.; Heikes, B.C.; Jacob, D.J.; Munger, J. W.; Dauce, B. C.; Keene, W. C.; Manbe, J. R.; Artz, R. S.; J. Geophys. Res. 1995, 100, 9335.

42. Kawamura, K.; Kaplan I. R.; Environ. Sci. Technol. 1987, 21,105 .

43. Gradel, T. E.; Eisner, T.; Tellus, Ser. B 1988, 40, 335.

44. Weathers, K. C.; Likens, G. E.; Bormann, F. H.; Bicknell, S. H.; Bormann, B. T.; Daube, B. C.;. Eaton, J. S.; Galloway, J. N.; Keene, W. C.; Kimball, K. D.; McDowell, W. H.; Siccama, T. G.; Miley, D. e Tarrant, R. A.; Environ. Sci. Technol. 1988, 22, 1018.

45. Sanhueza, E.; Andreae, M. O.; Geophys. Res. Lett. 1991, $18,1707$.

46. Enders, G.; Dlugi, R.; Steinbrecher, R.; Clement, B.; Daiber, R.; Eijk, S. G.; Haziza, M.; Helas, G.; Herrmann, U.; Kessel, M.; Kesselmeirer, J.; Kotzias, D.; Koutrtidis, K.; Kurth, H.; McMillen, R. T.; Roider, G.; Schürmann, W.; Teichmann, U.; Torres, L.; Atmos. Environ. Part A 1992, 26, 171.

47. Servant, J.; Kouadio, G.; Cros, B.; Delmas, R.; J. Atmos. Chem. 1991, 12, 367.

48. Atkinson, R.; Carter, W. P. L.; Chem. Rev. 1984, 84, 437. 49. Atkinson, R.; Atmos. Environ. Part A 1990, $24,1$.

50. Finlayson-Pittis, B. J.; Pitts, J. N. Atmospheric Chemistry: Fundamentals and experimental techiniques Wiley, New York, 1986.

51. Carter, P. W.; Atmos. Environ. Part A 1990, 24, 481.

52. Grosjean, E.; Grosjean, D.; J. Atmos. Chem. 1997, 27, 271.

53. Boubel, R. W.; Fox, D. L.; Turner, B. C.; Stern, C. A.; Eds; Fundamentals of air pollution Academic Press, San Diego, 1994, 3.ed., p.165.

54. Paulson, S. E.; Flagan, R. C.; Seinfeld, J. H.; Int. J. Chem. Kinet. 1992, 24, 103.

55. Grosjean, D.; Grosjean, E.; Williams, E. L.; Environ. Sci. Technol. 1994, 28, 186.

56. Hatakeyama, S.; Tononaka, T.; Weng, J.; Bandow, H.; Takagi, H.; Akimoto, H.; Environ. Sci. Technol. 1985; 19, 935.

57. Grosjean, D.; Atmos. Environ. 1984, 18, 1641.

58. Forstner, H. J. L.; Flagan, R. C.; Seinfeld; Environ. Sci. Technol. 1997, 31, 1345.

59. Jacob, J. D.; Wosfy, C. S.; J. Geophys. Res. 1988, 93, 1477.

60. Veyret, B.; Lesclaux, R.; Rayez, M. T.; Rayez, J. C.; Cox, R. A.; Moorgat, C. K.; J. Phys. Chem. 1989, 93, 2368.

61. McElory, W. J.; Waygoog; J. Chem. Soc., Faraday Trans. 1991, 87, 1513.

62. Chien, C.; Charles, M. J.; Sexton, K. S.; Jeffries, H.; Environ. Sci. Technol. 1998, 32, 299.

63. Mandronick, S.; Calvert, J. G.; J. Geophys. Res. 1990, 95, 5697.

64. Grosjean, D.; Atmos. Environ. 1983, 17, 2379.

65. Dagaut, P.; Wallington, T. J.; Liu, R.; Kurylo, M. J.; Int. J. Chem. Kinet. 1988, 20, 331.

66. Talbolt, R. W.; Vugen, A. S.; Harriss, R. C.; J. Geophys. Res. 1992, 97, 16531.

67. Norton, R. B.; J. Geophys. Res. 1992, 97, 10389.

68. Grosjean, D.; Parmar, S. S.; Environ. Sci. Technol. 1990, 24, 1021

69. Khare, P.; Satsangi, S.; Kumar, N.; Kumari, K. M.; Srivasta, S. S.; Atmos. Environ. 1997a, 31, 3867.

70. Granby, H.; Christensen, C. S.; Lohse, C.; Atmos. Environ. 1997a, 31, 1403 .

71. Sanhueza, E.; Santana, M.; Hermoso, M.; Atmos. Environ., Part A 1992, 26, 1421.

72. Khare, P.; Satsangi, S.; Kumar, N.; Kumari, K. M.; Srivasta S. S.; J. Geophys. Res. 1997, 102, 18997.

73. Grosjean, D.; Atmos. Environ. 1988, 22, 1637. 
74. Souza, S. R.; Carvalho, L. R. F.; Quim. Nova 1997, $20,245$.

75. Souza, S. R.; Vasconcellos, P.; Carvalho, L. R. F.; Atmos. Environ. Part A 1999, 33, 2563.

76. Lawrence, J.; Koutrakis, P.; J. Geophys. Res. 1996, 101, 9171.

77. Reiss, R.; Ryan, P. B.; Tibbetts, S. J.; Koutrakis, P.; J. Air Waste Manage. Assoc. 1995, 45, 811.

78. Winwarter, W.; Puxaubam, H.; Facchini, M. C.; Beltz, N.; Enderle, K.; Jaeschke, W.; Tellus, Part B 1988, 40, 348.
79. Munger, W.; Collett, J.; Daube, B. C.; Hoffmann, M. R.; Tellus, Ser. B 1989, 41, 230.

80. Maupeti, F.; Delmas, R. J.; J. Geophys. Res. 1994, 99, 16491. 81. Legrand, M.; Saigne, C.; Atmos. Environ. 1988, 22, 1011.

82. Kumar, N.; Kulshresestha, U. C.; Saxena, A.; Khare, P.; Kumari, K. M.; Srivasta, S. S.; J. Atmos. Chem. 1996, $23,81$. 83. Talbolt, R. W.; Harriss, R. C.; Gregory, G. L.; Sebacher, D. I.; Beck, M. S.; J. Geophys. Res. 1986, 91, 5173. 84. Grosjean, D.; Atmos. Environ., Part A 1990, 24, 2699. 